Colin Barrett - Blaž Martić i Marina Veverec

\title{
Mali Clancy
}

U mom gradu sigurno niste bili, ali znate taj tip. Izlaz s autoceste, industrijska zona, kino s pet dvorana, kilometar kvadratni grada nakrcan stoljetnim pabovima. Atlantik je blizu; blizu je kvrgava čeljust obale s rtovima pod vječitom najezdom galebova. Ljetne večeri; miris balege naliježe na pašnjake okolnih naselja dok ravnodušni volovi podižu glave da bolje osluhnu riku friziranih jurilica koje klinci ganjaju zabačenim cestama.

Mlad sam, a nas mladih ovdje nema mnogo, pa se može reći da se sve nas pita.

Nedjelja je. Gotov je vikend, taj trodnevni festival drobljenja. Nedjelja je dan pročišćenja i kajanja; dan omekšanih lubanja, uzburkanih želudaca i šupljih obećanja da se više nikada, ali nikada nećemo tako razvaliti. Veseli te što dan ide svome kraju prije nego što je uopće počeo.

Osam sati već je odavno prošlo, ali vani se još nije smračilo; topla svjetlost prožeta je onom ugodnom melankolijom koja prati srpanjske večeri na zapadu. Sa mnom za stolom, u prostoru za pušače vani pred Dockeryjem, sjedi Tug Cuniffe. Prostor za pušače uzak je komad betona sa stražnje strane paba koji gleda na rijeku. Mušice nam golicaju tjemena. Prugasto platno tende razapeto nosačima tu i tamo se, poput jedra, namreška na povjetarcu.

Naš je stol tik do rijeke i ugodno je slušati radijski šum usključale vode. Tu je još desetak ljudi. Većinu poznajemo, barem iz viđenja, a oni - svi oni znaju nas. Tug je jedan od onih koji se zaobilaze u širokom luku. Potajno ga zovu Velika Beba. Golem je i nepredvidljiv, sklon naletima gnjeva i izljevima bijesa. Pije neke tablete da ne ispadne iz ravnoteže, no ponekad se zainati ili prevari pa ih iz pretjerane samouvjerenosti prestane uzimati. Nekad mi to prizna i potkupi me viškom tableta, a nekad mi ne kaže ništa.

Tug je čudan, jer podigla ga je obitelj izobličena od bola u koju je, moglo bi se reći, njegova duša zalutala; pravo mu je ime Brendan, ali nije prvo dijete koje su Cuniffi tako nazvali. Njegova je majka prvi put rodila par godina prije nego što je dobila Tuga, no to je krhko dijete pokopano s trinaest 
mjeseci. Onda se rodio Tug. S četiri su ga godine prvi put odveli na glanbeighško groblje da položi cvijeće kraj samotne modre ploče na kojoj je ispucalom pozlatom bilo ugravirano njegovo ime.

Mamuran sam. Tug nije. On ne pije, i bolje da je tako. Mrcvarim pivo, pijuckam ga tako sporo da je skoro ishlapilo.

„Kako glava, Jimmy?” zagrakće Tug.

Dobar je, dobar, ali je na rubu, na samom rubu.

„Bila je i bolje”, priznam.

„Petak u Quillianu?”

„U Quillianu,” kažem, „onda u Shepherdu, pa Fandangu. U subotu repriza.” „Jesi ga kome metno?” upita.

„Marlene Davey.”

„O Bože”, kaže Tug. „Bože, bože, bože.”

Jezikom pročačka po kutnjacima.

Tug ima dvadeset četiri, a ja dvadeset pet, ali izgleda kao da me šiša za deset. Koliko znam, nevinost mu je još uvijek netaknuta. Dok smo bili u srednjoj za njim su slinile cure iz klasične i njihove mamice. Kao tinejdžer bio je zgodan, ali oko šesnaeste počeo je gomilati kile, pa su kile i ostale. Zbog debljine izgleda otužno; pokretanje i navigiranje tolike mase zahtjevan je i zamoran podvig. Brije se na nulu i nosi tamnu vrećastu robu, fura se na Marlona Branda iz Apokalipse danas.

„Ja i Marlene znamo se od davnih dana”, kažem.

Nisam ništa slagao. Od svih mojih veza, najbliža ozbiljnoj bila je ona s Marlene - i ako baš ne mogu reći da smo bili skupa, ne mogu reći ni da nismo, čak i nakon što je prošle godine ostala trudna s Markom Cuculannom. Malo poslije Božića rodila je dječaka i nazvala ga David po svom voljenom, pokojnom tati.

U petak sam naletio na nju u Fandangu. Okupila se uobičajena ekipa; cure u mikrominjacima i šiljastim petama, bombastičnih kovrča i iskvarcanih dekoltea boje mahagonija. Seljačine s okolnih 
farmi magarećih šija u kariranim košuljama zakopčanima do grla i s rukavima koje su zavrnuli do lakta za slučaj da ih netko pozove da iz vrele kravlje utrobe izvuku tele. U Fandangu je kao u zadimljenoj samici. Neon bljeska i pulsira, suhi led pršti. Zidove bez prozora trese raskalašeni bas. Spazio sam je krajičkom oka dok smo Dessie Roberts i ja trusili žestice za šankom. Vidjela me još prije i polako mi se primicala. Kao inače, sramežljivo smo se osmjehnuli jedno drugome, i točno smo znali što slijedi.

Naša je rutina ugodna kao što rutine inače znaju biti, ali je i zagonetna jer još traje.

Marlene živi s Angie, svojom mamom koja sve prihvaća i na sve pristaje i koja je čak i u tri ujutro sjedila za kuhinjskim stolom i pijuckala hladni čaj, spokojno listajući TV program. Marleneinoj mami bilo je drago što me vidi. Pristavila je čajnik i ponudila nam po šalicu. Pristojno smo odbili. Rekla nam je da mali David čvrsto spava na katu i da pripazimo da ga ne probudimo. U Marleneinoj sam se sobi potrbuške strovalio na hladan poplun; zoološki vrt plišanih životinja iz njezina djetinjstva bio je naslagan na dnu kreveta. Dok mi je Marlene povlačila hlače preko listova, pokušavao sam se prisjetiti imena svakom praščiću i zečiću s dugmastim očima.

„Boopsy, Winnie, Flaps... Rupert?”

E sad, moji su listovi gola, pjegava prostranstva blijedih, neoblikovanih mišića prošarana kuštravim crnim dlačicama; svaki put kad ih u ogledalu okrznem pogledom zaprepasti me njihova postojana ružnoća. No Marlene in je počela nježno mijesiti prstima. Polako mi se primicala bedrima pa procijedila: „Okreni se.” Treba cijeniti curu koja ugleda tako odvratne listove i svejedno sjedne na tebe.

„Dobra je ona”, kaže Tug.

Muha mu sleti na glavu i zaplete se u sićušnim dlačicama kose. Čini se da nije primijetio. Želim zamahnuti rukom i pljesnuti je.

Ali samo kažem: „To sigurno”, pa gucnem pivo.

I najednom pojavi se Marlene. U ovom gradu to se često događa; prizoveš nečije ime, i gle čuda, on se pojavi glavom i bradom. Prolazi kroz dvokrilna vrata u odrezanim trapericama, sunčane je naočale zataknula u crvene lokne i žustro liže sladoled u kornetu. Na sebi ima drečavo žuti topić da bolje istakne trbuh koji je nakon poroda toliko utegnula da izgleda napet poput hrta u trku. 
Tetovaža sunčanog sata obrubljuje joj pupak. Oči su joj boje bakrene patine, i da joj obrazi nisu izrovani ožiljcima od akni, bila bi prava ljepotica, moja Marlene.

Za njom ulazi Mark Cuculann. Marlene me spazi i trzne bradom prema meni; zna da sam tu, ali je na oprezu, jer zna da iza nje hoda Cuculann, a pokraj mene sjedi ogromni Tug Cuniffe.

„Eno Marlene”, kaže Tug.

„Aha.”

„Pa jel ona na kraju s tim Cuculannom il nije?”

Slegnem ramenima. Imaju dijete pa je valjda u redu da se igraju mame i tate; to i jesu. Što još s njim radi, to se mene ne tiče, kažem si. Uostalom, kažem si, trebam mu biti zahvalan što je umjesto mene primio metak očinstva.

„Bome dobro izgleda u zadnje vrijeme”, kaže Tug. „Oš je ić pozdravit?”

„Napozdravljali smo se mi u petak.”

„A možda ti je i bolje da se makneš”, kaže Tug.

Dlanom poklopim kriglu i počnem lupkati prstom po njezinu rubu.

„Jesi čuo šta kažu za malog Clancyja?” javi se Tug nakon kratke šutnje.

„Ne”, kažem.

„Neki tip s farme kod Enniscorthyja kaže da je vidio klinca koji odgovara opisu malog Clancyja s pazi sad ovo - s dvije žene, dvije žene u tridesetima. Stale su u kafić blizu njegove farme. Pričo je s jednom od njih. Pazi ovo, kaže da je jedna bila - Njemica. Pričala je onako nekako germanski, i onda su pitale, zapravo, ova je pitala kad ide trajekt za Rosslare. Vodale su sa sobom tog nekog klinca plave kose, šutljivog, malog. To je bilo prije par tjedana, samo ovaj nije odma povezo."

„Nekako germanski?” ponovim.

„Da, da”, kaže Tug.

Obrve mu poskakuju od uzbuđenja. Tug je opsjednut malim Clancyjem, mada su drugi već zaboravili na to. Wayne Clancy, desetogodišnjak, učenik iz Gurtlubbera u okrugu Mayo, nestao je prije tri mjeseca. Na školskom izletu u Dublin. Stajao je s učenicima i dvije učiteljice iz Gurtlubbera 
u centru grada, na nekom semaforu - upalilo se crveno, promet je stao, klinci su prešli cestu - a njega više nije bilo. Prvo su mislili da je mali Wayne nekud odlutao, da se pogubio u velikom gradu, ali ubrzo je postalo jasno da se nije izgubio, već da je nestao. Cijelog svibnja njegov je nestanak punio naslovnice dnevnih novina. Prema općeprihvaćenoj teoriji, nepoznati su ga počinitelji zgrabili još dok je Wayne stajao na semaforu, ili odmah poslije. Policija je pokrenula istragu, Clancyjevi su uputili uplakani apel pred kamerama... ali naišli su na zid i pred zidom su ostali. Nigdje maloga, nigdje tijela, nigdje pravog traga ni smjera u kojem bi se istraga mogla nastaviti.

Neko su se vrijeme svi bavili time jer je Gurtlebber blizu našeg grada. Ali život ide dalje, pa nas je malo po malo prestalo biti briga.

Tug nikako da zaboravi malog Clancyja. Ne može odoljeti mučnoj neizvjesnosti kojoj takve nedovršene priče daju maha. Plodonosnom kaljužom njegove mašte brojni se što ako množe poput crnog cvijeća. Ako ga pustiš, cijelu će noć bubetati o neobilježenim grobovima zalivenima vapnom, međunarodnim lancima trgovine djecom, prodaji organa, prisilnim inicijacijama u sekte.

Daj oladi, znam mu reći.

„Možda su lezbe”, kaže Tug. „Njemice lezbe. Znaš ono, ne mogu imat djece. Ne mogu na umjetnu oplodnju, ne mogu posvojit. Možda su očajne."

„Možda”, kažem.

„Mali Clancy izgledo je ko arijevac. Šta ne? Plava kosa, plave oči”, kaže Tug.

„Sva djeca izgledaju ko arijevci”, kažem, već pomalo živčan.

Terasom odjekne Marlenein smijeh, visoki drski kikot. Cuculann i ona pridružili su se drugom paru, Stephenu Gallagheru i Connie Reape. Cuculann je visok, pothranjen i žgoljav, poput mene; Marlene ima svoj tip. Kikoće se nečemu što je Gallagher rekao. Svi su ostali, pa i sam Gallagher, naizgled zbunjeni, no Marlene se smije i udara ga po ramenu kao da ga moli da prestane biti tako komičan.

„Al ne bi to bio ni najgori kraj za malog. Ustvari, ne bi opće bio kraj”, kaže Tug.

Kroz dvokrilna vrata ulazi konobarica i na pladnju nosi kvartet flauta za šampanjac. Marlene je dozove i, dršku po dršku, razdijeli čaše na čiji su rub nataknute jagode. Cuculann plati i dok 
Marlene na pladanj baca salvetu kojom je držala sladoled, izdajnički bljesak na njezinom prstenjaku ubode me u oko.

„Šta ne?” kaže Tug.

Posegne preko stola i spusti šapu na moju podlakticu pa je protrese.

„Bilo bi to jebeno, Tug”, kažem.

Ustukne pred oštrinom mog glasa. Moje su misli, želim mu reći, dio potrage za patnjom druge vrste, i ne, Tug, sad se ne mogu zamarati beskrajnim repovima priče o malom Clancyju.

„A tako”, kaže Tug.

Zarije ruku pod suprotni pazuh, kao da si vratima želi pričepiti prste.

„Nisi nešto od volje...” okrene se, pronjuši zrak, „i to zbog Marlene. Zbog one razvaljene pičke Marlene", kaže.

Odmahnem glavom. Coknem jezikom. Uperim prst u njega.

„Tug, ko ni bilo ko drugi ne biram kad ću ga i kome umočit, al daj malo pazi šta govoriš.”

Nasloni se i napne koliko je dug i širok.

„Govorit ću šta oću. I o kome god oću."

„A daj, jebote, stvarno si ko beba, velika beba!”

Tug ščepa stol objema rukama, osjetim kako se poda mnom podiže i podrhtava. Zgrabim piće i zavalim se u stolicu, a podmetači se otkotrljaju preko ruba. Tug se zaljulja, zaljulja se i stol, prevali se i tresne o beton. Gosti ciknu i poskoče.

Pažljivo kliznem sa stolice, prvo jednom pa drugom nogom, i ne skidam pogled s Tugovih očiju. Usta mu se iskrive u cer, diše ubrzano i grčevito.

„Oprosti, Tug”, kažem.

Nosnice mu se skupljaju i šire, dok se napokon ne umire do ujednačenog ritma.

„Dobro,” kaže, „dobro.” 
Dlanom protrlja nabore na lubanji i, vidno zapanjen, pogleda prevrnuti stol, kao da to nema nikakve veze s njim.

„Ajde,” kažem, „idemo.”

Iskapim pjenasti talog iz krigle i ostavim je na obližnjem stolu.

Ljudi nam se miču s puta dok prolazimo. Pratim ga u stopu.

Znam što misle. Velika Beba opet šizi. Velika Beba opet divlja. Velika Beba i njegov čudni prijatelj Jimmy Devereux.

„Ej Marlene!” dobaci Tug veselo kad se dokotrljamo do njezina stola.

Marlene je mirna, kao inače. Cuculann pored nje sjedi sav napet i stisnut, spreman za akciju. „Ej, momčino”, kaže Marlene.

Pogleda u mene.

„I malo manja momčino.”

„Jel vrijeme za čestitke?” upitam.

Uhvatim je za prste, ispravim in da bolje pogledam. Marlene istrgne ruku i sakrije je drugom.

„Kasno ti je sad”, nasmijem se. „Vidio sam. Kamenčina i pol.”

„Nego šta”, kaže Cuculann.

„A baš je krasan”, kaže Tug.

Osjećam zloslutnu blizinu te mase za svojim leđima, opet je na mojoj strani, spreman planuti na moj znak.

Marlene isturi donju usnu preko gornje i pogledom mi kaže: sad me dobro slušaj.

„Jimmy, napokon sam sretna”, kaže. „A sad, molim te, odjebi.”

Večernje sunce ispred Dockeryja na pitoresknim je mukama, nebo natapaju pjenušave nijanse crvene i ružičaste. Povjetarcu izbijaju zubi. Komadići stakla pod nogama krckaju kao šljunak. Uz cestu su poredani automobili, a među njima je i sićušna, izblijedjela srebrna starudija u kojoj se 
Cuculann drnda po gradu. Odmara na nogostupu, kao šaka u oko, a s unutarnje strane vjetrobrana zalijepljena je naborana naljepnica s oznakom autoškole.

„Vidi na šta to liči”, kažem.

Ispruženim dlanom odalamim po izraubanoj haubi.

Tug me začuđeno pogleda.

„Cuculannov auto”, kažem.

„Izgleda ko pernica”, kaže Tug i nasmije se.

„Šteta je da svoju buduću ženu vozi u takvoj krntiji”, kažem.

„Grozno, grozno, grozno”, složi se Tug.

„Tug, jesi presto pit tablete?” kažem.

„Ne”, zarokće.

Nasloni svoj ogromni dlan na krov auta i zaljulja ga naprijed-nazad, amortizeri zacvile u znak protesta. Tug nikada nije znao lagati; zbog svoje veličine, fizičke prednosti, nikada se nije naučio pretvarati. Ako si dovoljno velik, uvijek možeš reći istinu, uvijek možeš reći što misliš.

„Jel bi ti bilo jako teško prevrnuti ga na krov”, kažem.

„Ništa lakše”, kaže Tug.

Ljulja ga i ljulja toliko jako da gume sad već luđački škripe, a cijeli auto poskakuje u mjestu.

Parkiran je pod kutom, paralelno s rubnikom koji je par centimetara viši od ceste - pod kutom koji Tugu olakšava posao. U pravom se trenutku Tug sagne i zavuče ruku pod dno starudije pa svom snagom potegne. Gume uzlete s rubnjaka. Auto se na trenutak zaustavi u zraku, ostane na boku: ugledam dno kojim se proteže krvožilni sustav pocrnjelih cijevi, a zatim se Tug zaleti i prevrne starudiju na krov uz glasan zvuk drobljenja. Stražnji se prozor smrska, staklo nam se po nogama razlomi u sićušne dijamante. Tug posegne i umiri jedan od kotača koji se okreću u prazno.

„Bravo momčino."

Tug dašće, obrazi mu gore. Slegne ramenima. Cestom prolazi auto. Dječja se lica tiskaju uz stražnji prozor ne bi li uhvatila pogled na prevrnutu starudiju. Neki starkelja izađe iz Dockeryja, 
nabije izlizani šešir na drhtavu glavu pa ga namješta. Labavo zavezana kravata lepeta mu o rumeno, naborano lice. Starkelja nabaci žućkasti osmijeh.

„Dečki, kako smo?” kaže.

„Jebeno", kaže Tug.

Starkelja nas pozdravi pa prođe kraj prevrnutog auta kao da ništa nije vidio.

Spustim pogled i ugledam, napola u autu a napola izvan njega, smeđu kožnu torbu čiji se sadržaj rasuo po slivniku. Svežanj maramica, sitniš, zgužvani omoti bombona, kemijska olovka, računi, antiperspirant u stiku, ruž u zlatno obrubljenom crnom cilindru. Podignem ga, skinem poklopac. Odem do stražnjih vrata i primim se posla. Velikim crvenim slovima ispišem svoju molbu:

\section{U D A J SEZAMENE}

„Jebote”, kaže Tug, a vilica mu preskoči. „Bome opako, Jimmy.”

Slegnem ramenima i spremim ruž u džep. Ostalo skupim i vratim u torbicu. Provučem je kroz razbijeni prozor i uguram pod suvozačko sjedalo.

„Hoćemo do tebe?”

„Ajmo”, kaže Tug.

Tug živi s mamom u naselju Farrow Hill s druge strane rijeke. Njegova tate, kao i Marleneina, više nema, već je deset godina pod zemljom. Starom je Cuniffu prsnulo srce dok je iz zapaljene štale spašavao ždrijebe. Tugova majka slatka je stara ruševina od alkoholičarke koja, udubljena u televiziju i svoje pokojne, dane provodi racionirajući džin na prastarom kauču izbušenom federima. Pozdraviš je, a ona ti uputi ugodan, premda skeptičan osmijeh; uglavnom nema pojma jesi li dio televizijskog programa, plod njezine mašte ili si zbilja pred njom, stvarna osoba. Ponekad me zove Tug ili Brendan, a Tuga nazove Jimmy. Nekad Tuga zove imenom njegova oca. Tug kaže da nema smisla ispravljati je. Otkako se prepustila zagrljaju senilnosti, raspoznavanje ljudi nije joj baš bitno. Usput smo svratili do Carcettija po pomfrit, koji smo potamanili šetajući stazom uz rijeku. Vitke se trske taru jedna o drugu poput svježe naoštrenih žileta. Mokre stijene, crne kao ugalj, ljeskaju se na obali u svojoj postelji od algi. Zdrobljene limenke Strongbowa, Dutch Golda i Karpackija utonule 
su u mulj poput drevnih iskopina. Zrakom romore rojevi mušica. Naše glave putujući su planeti na kojima se goste.

Drveni se most u daljini proteže preko rijeke.

Mostom se navodno ne smije prelaziti. Ranije ove godine proljetna je bujica donijela stablo koje se zabilo u most i ondje nastanilo. Pod kutom od četrdeset i pet stupnjeva ogromno se kvrgavo deblo svom silinom navalilo na polomljene grede i rascijepane stupove ograde. Premda se most ulegao po sredini, još uvijek stoji. I umjesto da se trupac skloni, a most popravi, gradsko je vijeće s obje strane obale dalo podignuti labave žičane ograde s oštro sročenim natpisima upozorenja, koji kažu da onima koji planiraju prijeći prijeti kazna i opasnost po život.

No most je najbrži prečac do Farrow Hilla, pa su ljudi poput Tuga, unatoč upozorenjima vijeća, porušili dio ograde i nastavili se služiti mostom kad trebaju do grada i natrag.

Na putu do mosta ugledamo troje djece kako se igraju; dvije curice i nešto stariji dječak. Djevojčicama je možda pet ili šest godina, a dječaku nekih devet, deset.

Dječak ima bijelu kosu - ne plavu, bijelu. Nosi izblijedjelu pamučnu potkošulju krem boje i sjajnu ljubičastu trenirku s nogavicom poderanom do koljena. Curice na sebi imaju iste neuredne roza kompletiće. Na dječakovu licu iscrtane su šare koje podsjećaju na ratničke boje nekog plemena; crveno-bijele linije ispod očiju i crna duž nosa. U ruci drži aluminijsku šipku - mogla bi to biti karniša, štaka ili drška mreže za pecanje. Jedan je kraj šipke spljošten u špicu.

„Šta si ti, indijanac?” upita ga Tug.

„Ja sam kralj!” zareži dječak.

„Kakvo ti je to oružje? Toljaga, mač?” kažem.

„To je koplje."

Prekorači preko uleknute ograde i skoči na stazu. Izvodi neke borilačke poteze: šipkom siječe zrak pa je kovitla iznad glave, vješto je premješta iz jedne ruke u drugu. Na kraju jednom nogom iskorači i uperi vrh šipke u Tugova prsa.

„Ovo je moj most”, kaže i iskesi zube.

„A šta ako bi mi prošli?” kaže Tug. 
„Ne može dok ja ne kažem!”

Tug mu ponudi zgužvanu vrećicu s krumpirićima.

„Platit ćemo. Jeste za krumpirić, vaše veličanstvo?”

Dječak gurne ruku u vrećicu i izvadi punu šaku krumpirića natopljenih octom. Probere po šaci, pronjuši, a onda razdvoji slijepljene krumpiriće i razdijeli ih curicama. One ih progutaju, jednog po jednog. Zabace glavu, a grla im, kao pilićima, halapljivo gutaju.

„Drage moje koke”, kaže dječak i obje ih potapša po glavi.

Djevojčice se stanu cerekati.

„Ne smijete ništa uzimat od nekog koga ne znate”, kaže Tug.

„Ja sam im dao krumpiriće”, kaže dječak, lupajući se kopljem po prsima. „Šta vas vodi preko mosta?"

„Tražimo nekoga. Jednog klinca. Plav ko ti”, kaže Tug. „Malo i sličite. Otišo je, i niko ne zna di je.” Dječak se namršti. Ponovno stane na ogradu pa se zagleda u zavojitu rijeku.

„Takvog ovdje nema”, konačno izusti. „Vidio bih ga ja. Ja sam kralj, ja sve vidim.” „A moramo pokušat”, kaže Tug.

Tug, pusti ga, želim mu reći, ali prešutim. To je važan dio prijateljstva: prešutjeti ono što želiš reći. Okrenem se i pogledam niz stazu, prema putu kojim smo došli. Na vrhu brežuljka je cesta, a iza njega čuče oronuli obrisi grada. U daljini čujem, ili mi se učini da čujem, komešanje, dreku, i zamislim Marka Cuculanna kako se ispred Dockeryja iživljava na prevrnutoj olupini. Pored njega, prekriženih ruku, stoji Marlene, i točno vidim izraz njezina lica, zelena patina njenih očiju blista kroz sužene kapke, osmijeh joj se otima s usana, usana iste nijanse kao i prosidba naškrabana na stražnjim vratima. Napipam poklopac od ruža, izvadim ga iz džepa i dam curici. „Još poklona”, kažem. „Nego Tug, ajmo mi lagano.”

Tug zakorači da zaobiđe dječaka. Dječak zamahne šipkom i vrhom ga ubode u trbuh. Tug zgrabi šipku i zabije je dublje, savijajući je. Odglumi uzdah i rukom zagrebe kroz zrak. 
„Ubio si me”, zakriješti.

Otetura unatrag, škripava mu koljena popuste pa se razvali koliko je dug i širok, zabije lice ravno u travu i, kao da se klanja Bogu, isturi guzicu prema nebu.

„Sad nema nazad”, kažem.

Dok leži skvrčen kao fetus nožnim ga prstom bocnem u rebra. Beživotno se zaljulja. Dječak priđe, ponovi moj pokret i zarije mu nožni prst u rame. Curice utihnu.

„Kako ćeš ovo objasnit mami?” kažem.

Oči mu zasuze, ali glavu i dalje drži visoko.

„Eno ga na, sad će se još i rasplakat”, kažem.

Tug, mekog srca, ne može ostati mrtav. Promrmlja, podigne glavu, naceri se. Odmjeri dječaka. Ustane.

„Nemoj plakat, malecki”, kaže. „Bio sam mrtav, al sam usto iz mrtvih.”

S mukom prekorači ogradu i krene mostom, a ja za njim.

„Doviđenja, vaše veličanstvo!” vikne Tug.

Dok ga zaobilazim, dječak nas mrko promatra prekriženih ruku, aluminijska šipka naslonjena mu je na rame.

„Ako propadnete, ja vam ne mogu pomoć”, upozori nas.

Pod nama most škripi. Na pola puta tanko se kvrgavo granje nasukanog drveta ispriječi poput vještičjih prstiju, sežući prema našim licima, pa ih razmičemo i sklanjamo s puta.

„Nego reci mi, Tug”, kažem.

„Šta?”

„Reci mi još nešto o malom Clancyju. O tim Njemicama lezbama.”

I Tug počne pričati, razvijati teorije, a ja ga zapravo ni ne slušam, i to je u redu. Dok trabunja, gledam kako mu glava poskakuje, promatram nabore i brazde njegova izbrijanog potiljka. Gledam mu vrat, duboki prorez u salu koji sliči na krnjavi kes, i planinsku širinu njegovih klatećih ramena. 
Sjetim se fotografije malog Clancyja, izrezane iz nedjeljnih novina. Tug je čuva u svojoj sobi pričvršćenu na pluteni pano. To je ona svima poznata fotografija: rođendanska proslava, mali plavi Clancy, na glavi prevelika kruna od krep-papira, široki tragični osmijeh otkriva neravne zube, oči širom otvorene, izgubljen u blaženom zanosu trenutka. Sjetim se Marlene. Sjetim se njezina klinca, tako je malo falilo da bude moj. Sjetim se njezina osunčanog pupka, njezina trbuha toliko napetog da je mogu poleći na leđa, bacati kovanice i gledati kako se od njega odbijaju. Svi imamo nešto što ne možemo pustiti.

Daske načetog mosta uvijaju se i cvile pod nama, a kad prijeđemo na suprotnu stranu i ponovno zakoračimo na čvrsto tlo, preplavi me bujica neobjašnjive zahvalnosti. Ispružim ruku, potapšam Tuga po ramenu i okrenem se da pozdravim malog kralja i njegove cerekave dvorjanke. Ali kad pogledam preko uzavrelog vrtloga crne vode, djece više nema.

\section{c) (1) (9)}

Creative Commons Attribution-NonCommercial-NoDerivatives 4.0 International License 